\title{
Auditorias Remotas são possíveis? Como fazer?
}

\author{
Marcello Guimarães Couto \\ \marcello@hgb.com.br
}

1. HGB Consultoria e Gestão.

\section{Histórico do Artigo:}

Recebido em: 06 de junho de $2020 \quad$ Aceito em: 10 de agosto de $2020 \quad$ Publicado em: 31 de agosto de 2020

Resumo: As técnicas e métodos para auditorias remotas já eram previstas e aceitas antes mesmo do surto de COVID19. Com a pandemia e a necessidade de distanciamento social, tornaram-se uma ferramenta frequente e amplamente utilizada, nesta fase que chamamos agora de "novo normal". Este artigo aborda a sua previsão normativa, os principais cuidados e a sua viabilidade.

Palavras-chave: Auditorias remotas, Auditoria, ISO 19011, Certificação.

\section{Are Remote Audits possible? How to do it?}

Abstract: The techniques and methods for remote audits were already foreseen and accepted even before the outbreak of COVID-19. With the pandemic and the need for social distance, they have become a frequent and widely used tool, in this phase that we now call the "new normal". This article discusses its normative forecast, the main care and its viability.

Keywords: Remot audits, Audit, ISO 19011, Certification.

\section{¿Son posibles las auditorías remotas? ¿Como hacer?}

Resumen: Las técnicas y métodos para las auditorías remotas ya estaban previstas y aceptadas incluso antes del brote de COVID-19. Con la pandemia y la necesidad de distanciamiento social, se han convertido en una herramienta frecuente y ampliamente utilizada, en esta fase que ahora llamamos la "nueva normalidad". Este artículo trata sobre su predicción normativa, la atención principal y su viabilidad.

Palabras clave: Auditorías remotas. Auditoría, ISO 1901l, Certificación. 
Em épocas de isolamento social, muitos clientes e alunos têm nos perguntado como será o seu ciclo de certificação e como serão as próximas auditorias, internas ou externas. Então, em resposta a estas demandas, este artigo explora os principais documentos e normas oficiais sobre o tema e tem o objetivo de esclarecer as informações oficiais sobre a viabilidade e o "como" executar auditorias remotas.

Inicialmente é importante lembrar que há auditorias de $1^{\text {a }}$ parte (também conhecidas como internas, embora possam ser feitas por pessoal externo), onde a empresa audita seu próprio sistema, auditorias de $2^{\mathrm{a}}$ parte (qualificação de fornecedores) e de $3^{\mathrm{a}}$ parte (certificação).

Há no momento tanto regras para auditorias de $1^{\mathrm{a}} \mathrm{e} 2^{\mathrm{a}}$ partes quanto para auditorias de certificação.

Explicando: Os requisitos da norma ABNT NBR ISO 19011:2018 se aplicam às auditorias de $1^{\mathrm{a}}$ e $2^{\mathrm{a}}$ partes, enquanto os requisitos da ABNT NBR IS0/ICE 17021-1:2016, IAF MD 4 e perguntas frequentes (FAQ) do IAF para o surto de COVID 19 se aplicam às auditorias de $3^{\text {a }}$ parte (certificação).

Importante antes de desenvolver o tema harmonizar alguns conceitos.

\section{Termos e definições:}

\subsection{Site virtual (IAF MD4:2018)}

Local virtual onde uma organização cliente executa trabalho ou fornece um serviço usando um ambiente on-line que permite que pessoas executem processos independentemente de locais físicos.

Nota 1: Não pode ser considerado site virtual, um local onde os processos devem ser executados em um ambiente físico, por exemplo, armazenagem, fabricação, laboratórios de ensaios físicos, instalação ou reparos de produtos físicos.

A própria norma ISO 19011 esclarece que Auditorias virtuais são conduzidas quando uma organização realiza trabalho ou fornece um serviço usando um ambiente online que permita que pessoas executem processos independentemente de locais físicos (por exemplo, intranet da organização, uma “nuvem computacional”).

\section{5 - ESCOpo da auditoria (ISO 19011:2018)}

abrangência e limites de uma auditoria (3.1) 
NOTA 1 de entrada: O escopo da auditoria geralmente inclui uma descrição dos locais físicos e virtuais, funções, unidades organizacionais, atividades e processos, assim como o período de tempo coberto.

NOTA 2 de entrada: Um local virtual é onde uma organização realiza trabalho ou fornece um serviço usando um ambiente on-line, permitindo que pessoas executem processos independentemente de locais físicos.

Temos aqui então uma diferença importante de site virtual para auditoria remota. A auditoria remota é aquela realizada usando Técnicas de Informação e Comunicação - TIC (videoconferências, realidade aumentada, realidade virtual, filmagens, drones, Zoom, WhatsApp, Microsoft Teams, dentre outros), onde o auditor, remotamente (sem estar presente fisicamente) realiza a auditoria.

Explicando: de acordo com a IS0 19011, auditoria de um local virtual é algumas vezes referida como auditoria virtual. Auditorias remotas se referem ao uso de tecnologia (TIC) para coletar informação, entrevistar um auditado etc., quando métodos “cara a cara” não são possíveis ou desejáveis.

Mesmo antes do surto de COVID-19 as técnicas de auditoria remota e para auditar sites virtuais já eram previstas nos documentos acima, sendo que as FAQs do IAF para o surto de COVID 19 aumentaram a abrangência e aplicabilidade das mesmas.

\section{A IS0 19011:2018 e os métodos de auditorias virtuais/remotas - Para auditorias de $1^{\mathrm{a}}$ e $2^{\mathrm{a}}$} partes

Da leitura do texto da norma ISO 19011 percebe-se que uma de suas inovações para a versão de 2018 foi exatamente a de incluir a possibilidade de técnicas de auditoria remota, alinhada com os avanços de recursos tecnológicos que viabilizam estas atividades.

Esta nova norma trouxe em seu Anexo "A" importantes diretrizes para a realização de auditorias remotas, dentre outras:

- Garantir que a equipe auditora utilize protocolos de acesso remoto incluindo dispositivos requeridos, software etc.;

- No caso de se fazer cópias de captura de tela de documentos de qualquer tipo, solicitar com antecedência a permissão e considerar confidencialidade e segurança, bem como nunca gravar pessoas sem sua permissão 
- Solicitar e utilizar para o seu entendimento do layout do local plantas baixas/diagramas do local remoto

- Garantir que a equipe auditora utilize protocolos de acesso remoto previamente combinados, incluindo dispositivos, software etc.;

- Realizar verificações técnicas antes da auditoria para assegurar que não haja falhas na comunicação e nos métodos de troca de informações;

- Ter planos de contingência e comunicá-los (por exemplo, interrupção de acesso, uso de tecnologia alternativa), incluindo fornecimento de tempo extra de auditoria, se necessário.

A norma ISO 19011 também dedica um capítulo especial para a condução de entrevistas, explicando que, além de serem um método importante de coleta de evidências, deveriam ser adaptadas à situação e à pessoa entrevistada, presencialmente ou por outros meios de comunicação. Esta mesma norma, neste tópico, estabelece que o auditor esteja ciente da limitação da comunicação não verbal em auditorias remotas e sites virtuais, direcionando um cuidado a mais no tipo de perguntas e questões a serem aplicadas para buscar a evidência objetiva.

Auditorias remotas/virtuais de certificação e a ISO/IEC 17021-1 (para auditorias de $3^{\mathbf{a}}$ parte):

A norma ABNT NBR ISO/IEC 17021-1:2016, como comentado, em conjunto com o documento do IAF - IAF MD 4:2018 (Documento mandatório do IAF para o uso de tecnologias de informação e comunicação (TIC) para fins de auditoria/avaliação) estabelece os requisitos para um Organismo de Certificação realizar suas auditorias de $3^{\text {a }}$ parte.

A norma IS0/IEC 17021-1 prevê a auditoria remota em 3 requisitos (cláusulas), a saber:

\section{$\underline{6.2 \text { Controle operacional }}$}

Nesta cláusula a norma estabelece que a certificadora deve considerar o nível apropriado e o método de controle das atividades executadas, incluindo seus processos, áreas técnicas das operações do organismo de certificação, competência do pessoal, linhas de controle gerencial, informação e acesso remoto às operações, incluindo registros.

\subsubsection{Preparacão do plano de auditoria}


0 plano de auditoria deve ser apropriado aos objetivos e ao escopo da auditoria. 0 plano de auditoria deve incluir ou fazer referência no mínimo ao seguinte:

as datas e lugares onde as atividades de auditoria no local serão realizadas, incluindo visitas a sites temporários e atividades de auditoria remota, conforme apropriado;

\section{$\underline{9.4 \text { Conduzindo auditorias / 9.4.1 Generalidades }}$}

Se e quando alguma ou toda a parte da auditoria for feita usando técnicas remotas, meios eletrônicos ou quando o local for virtual, a certificadora deve garantir que que estas atividades sejam conduzidas por pessoal com a competência apropriada.

Importante esclarecimento é feito na 'nota' desta cláusula:

NOTA: Auditorias in loco" podem incluir acesso remoto a sites eletrônicos que contenham informações pertinentes à auditoria do sistema de gestão. Pode ser considerado o uso de meios eletrônicos para a condução de auditorias.

Comentaremos agora parte do IAF MD (documento mandatório do IAF) sobre TIC (Tecnologias de Informação e Comunicação), ou, no jargão popular, auditoria remota. Ressaltamos novamente que este documento se aplica a auditorias de $3^{\text {a }}$ parte.

\section{Anexo D - Documento mandatório do IAF para o uso de Tecnologias de Informação e Comunicação (TIC) para fins de auditoria/avaliação - IAF MD 4:2018}

Em sua introdução, este documento explica que à medida em que a Tecnologia da Informação e Comunicação (TIC) se torna cada vez mais sofisticada, é importante poder utilizála para melhorar a eficácia e a eficiência das auditorias/avaliações, e para apoiar e manter a integridade do processo de auditoria/avaliação.

Esta TIC pode ser utilizada para coleta, armazenamento, recuperação, processamento, analisar e transmitir informações.

Consideram-se aqui software e hardware tais como smartphones, dispositivos portáteis, laptops, desktops, drones, câmeras de vídeo, tecnologia wearable, inteligência artificial e outros.

0 documento também contém uma lista exemplificativa (exemplos de TIC) para auditorias: 
- reuniões por meio de teleconferência, incluindo áudio, vídeo e compartilhamento de dados;

- auditoria/avaliação de documentos e processos de certificação/acreditação por meio de acesso eletrônico remoto, de forma síncrona (em tempo real) ou assíncrona (quando aplicável);

- gravação de informações e evidências por meio de câmeras still, ou gravações de áudio/vídeo;

- permissão de acesso visual/áudio a locais remotos ou potencialmente perigosos.

Importante notar que ambos, auditor e auditado, devem tomar medidas para garantir que a segurança e a confidencialidade sejam mantidas durante as atividades de auditoria/ avaliação.

Em seu item 1. ESCOP0, o documento esclarece que é permitida a aplicação coerente do uso da tecnologia da informação e comunicação como parte da metodologia de auditoria/avaliação.

Reforça que o uso de TIC não é obrigatório, mas se utilizado como parte da metodologia de auditoria/avaliação, é obrigatório estar em conformidade com este documento (IAF M D 4). Ressalte-se novamente que este documento se aplica às auditorias de $3^{\text {a }}$ parte.

\section{Perguntas frequentes (FAQ) do IAF sobre o Surto de COVID-19 (para auditorias de $3^{\text {a }}$ parte)}

Como consequência do surto de COVID-19, 0 IAF (International Accreditation Forum) publicou um documento oficial com uma série de perguntas e respostas sobre como serão as auditorias de $3^{\mathrm{a}}$ parte a partir de então.

0 documento esclarece que as perguntas frequentes são algumas das perguntas mais frequentes em algumas (mas não em todas) das áreas em que os membros do Organismo de Acreditação (AB) do IAF e seus organismos de certificação (CBs) acreditados praticam. As perguntas e respostas não pretendem ser exaustivas; no entanto, eles constituem um entendimento comum e uma orientação para gerenciar, de maneira harmonizada, as atividades de avaliação da conformidade na situação específica do COVID-19.

Neste artigo foram separadas algumas perguntas e respostas diretamente aplicáveis às auditorias de certificação: 
Auditorias Remotas são possíveis? Como fazer?

Perguntas frequentes do IAF

P2: É permitido usar avaliacões e auditorias remotas para manter a validade das certificacões acreditadas durante a crise do COVID-19?

R2: Sim. A Declaração da IAF sobre COVID-19 referenciou o uso de avaliações remotas e o documento obrigatório a ser Usado por acreditadores e certificadoras, IAF MD4: 2018 Documento Obrigatório da IAF para o Uso da Tecnologia da Informação e Comunicação (TIC) para fins de auditoria e avaliação. Além disso, também há documento informativo sobre os princípios para avaliações remotas - IAF ID12: 2015 [...]

\section{P5: É possível executar uma auditoria de certificacão completa remotamente?}

R5: Sim, em teoria é possível, se para o esquema específico, todos os requisitos puderem ser avaliados remotamente, incluindo a observação de atividades. No entanto, isso pode mudar para esquemas específicos.

\section{Por que auditorias remotas precisam de um tempo adicional na preparação (para} auditorias de $1^{\mathrm{a}}, 2^{\mathrm{a}}$, e $3^{\mathrm{a}}$ partes):

Tenho visto no mercado não só certificadoras, mas empresas que prestam serviços de auditoria de la e 2a partes terem dificuldade para justificar por que necessitam de um tempo a mais (o que, é claro, tem um custo) no planejamento de uma auditoria remota.

Inicialmente é importante lembrar que a auditoria é remota, ou seja, o auditor não estará na planta, local, canteiro, site ou escritório da empresa fisicamente. Por mais que a tecnologia de comunicação tenha avançado - e muito - convenhamos que interagir via Zoom, FaceTime, Skype, WhatsApp, Teams ou outra ferramenta sempre elimina parte da comunicação da qual os auditores dependemos muito - o fator "olho no olho" e a leitura da comunicação não verbal.

Some-se a isso, claro, a questão da inspeção visual das instalações - o que, sim, pode ser ajudado, por exemplo, com um drone, realidade aumentada, realidade virtual ou uma simples chamada por vídeo, orientada pelo auditor. Mas é claro que utilizar estes recursos requer planejamento, e, principalmente, intimidade de ambos os lados - auditor e auditado - com a ferramenta.

Uma outra questão são as entrevistas. Com quem o auditor falará? Quando? Por meio de qual ferramenta? E o entrevistado selecionado, de fato domina a ferramenta?

Uma quarta questão é quanto à análise de documentos e evidências. Deve ser muito bem planejada, pois sabemos que estar sentado fisicamente ao lado do auditado e ele mostrar um 
registro tem um ' timing' totalmente diferente de solicitar algo, ele achar o arquivo, compartilhar a tela, rolar a tela no aplicativo e... bem, acho que deu para entender, né?

É fato notório e sabido que o andamento de uma auditoria virtual não é similar ao andamento de uma auditoria presencial. Portanto, devem-se notar estes fatores, por exemplo:

1 - Ao apresentar documentos, depende-se do recurso "compartilhar tela" do programa de meeting, o que gera uma latência na rolagem da barra do documento, gerando atraso. Neste tempo a mais de planejamento, procuramos identificar quais são os documentos mais complexos e já recebê-los por e-mail, para que possa ser feita leitura diretamente na segunda tela do auditor, durante a auditoria online.

2 - Inspeção visual à área: neste tempo a mais de planejamento faz-se com o auxílio de equipamentos (já citados acima) a visita virtual/ inspeção visual à área, o que consome tempo e costuma não dar tempo na auditoria online normal.

3 - Seleção de amostra e agendamento de entrevistas - considerando que a amostragem de auditoria deve ser estratificada ao longo do tecido social da empresa, e, claro, sempre uma decisão do auditor, sem permitir interferência externa, faz-se necessário identificar, após decidir a amostra (e para isso neste tempo a mais de planejamento tem-se acesso à lista de todos os envolvidos nos processos auditados) conhecer o grau de facilidade com que cada colaborador tem à ferramenta de meeting, para que, além de marcar o horário da entrevista, no caso de colaboradores com menos intimidade com a ferramenta, eles possam ser orientados antes do início da auditoria, evitando assim contratempos no dia da auditoria.

4 - Disponibilidade de outras técnicas de TIC - Tecnologia de informação e comunicação - neste um dia a mais convenciona-se quais recursos poderão estar disponibilizados pela empresa, tais como realidade aumentada, realidade virtual, ferramentas de meeting, drones, filmadoras etc.

Claro que esta lista não é exaustiva, é exemplificativa, mas já deixa claro que estas informações todas impactam sobremaneira no planejamento e no plano da auditoria online.

De fato, quando foi publicada, a norma IS0/IEC 17021-1 (para auditorias de 3 a parte) foi tímida em detalhar o processo de auditorias remotas, embora tenha claramente previsto sua possibilidade. 0 detalhamento da realização de auditorias remotas ficou a cargo do documento mandatório do IAF (IAF MD 4), citado no início deste artigo e do documento de respostas frequentes do IAF.

0 Organismo de certificação, então, poderá conduzir auditorias remotas/virtuais, desde que atenda aos requisitos tanto do IAF MD4 quanto os da ISO/IEC 17021-1 explicitados acima. 
Importante salientar que há etapas da auditoria e processos que, por sua natureza, provavelmente não poderão ser executados por meio remoto, como, por exemplo, a coleta de evidências na produção de uma fábrica. De fato, normalmente o uso de técnicas de auditoria remota é combinado com as técnicas de auditoria presencial. A análise crítica de que processos e requisitos podem ser feitos remotamente é uma das decisões mais importantes no planejamento da auditoria, em uma análise de riscos do mesmo. Estas orientações são para auditorias de $3^{\mathrm{a}}$ parte.

Para auditorias de $1^{\mathrm{a}}$ e $2^{\mathrm{a}}$ partes, embora ainda seja um método de auditoria pouco explorado, é perfeitamente possível e previsto na norma IS0 19001:2018 que as auditorias remotas/virtuais sejam feitas, desde que respeitadas as diretrizes estabelecidas pela norma.

Conclui-se que atualmente, e principalmente durante o surto de COVID-19, tanto para as auditorias de $1^{\mathrm{a}}, 2^{\mathrm{a}}$ e $3^{\mathrm{a}}$ partes a auditoria remota é perfeitamente possível e prevista e, sob certas condições, mediante uma análise de risco, até mesmo de representar a totalidade de uma auditoria.

\section{REFERÊNCIAS BIBLIOGRÁFICAS}

ASSOCIAÇÃO BRASILEIRA DE NORMAS TÉCNICAS. ABNT NBR ISO 19011/2018: Diretrizes para auditorias de sistemas de gestão. Rio de Janeiro, 2018.

ASSOCIAÇÃO BRASILEIRA DE NORMAS TÉCNICAS. ABNT NBR IS0/IEC 17021-1:2016: Avaliação da conformidade Requisitos para organismos que fornecem auditoria e certificação de sistemas de gestão Parte 1: Requisitos. Rio de Janeiro, 2016.

BERTOLINO, Marco Túlio \& COUT0, Marcello. Handbook do auditor e do auditado em sistemas de gestão: Técnicas \& Comportamento. $1^{\circ}$ EDIÇÃo - NITERÓI, RJ: Produção Independente com apoio SGI 68, 2020.

BERTOLINO, Marco Túlio \& COUT0, Marcello. Sistemas de Gestão Integrados: ISO 9001 + IS0 14001 + IS0 45001, com foco em resultados. $2^{\circ}$ EDIÇÃo - NITERÓI, RJ: Produção Independente com apoio SGI 68, 2020.

IAF Frequently Asked Questions COV-ID-19 0utbreak - https://iaffaq.com (acesso em 14 de Agosto de 2020)

IAF Mandatory Document for the use of Information and Communication Technology (ICT) for auditing/assessment purposes - Issue 2 - (IAF MD 4:2018) - https://www.iaf.nu/upFiles/IAF\%20MD4\%20Issue\%202\%2003072018.pdf (acesso em 14 de Agosto de 2020) 